\title{
Speech and Language Therapy Service Delivery: Overcoming Limited Provision for Children
}

Luis M.T. Jesus (corresponding author)

School of Health Sciences (ESSUA) and Institute of Electronics and Informatics

Engineering of Aveiro (IEETA)

University of Aveiro

3810-193 Aveiro

Portugal

e-mail:1mtj@ua.pt

Joana Martinez

Institute of Electronics and Informatics Engineering of Aveiro (IEETA)

University of Aveiro

3810-193 Aveiro

Portugal

e-mail: joanamartinez@ua.pt

Ana Rita Valente

Institute of Electronics and Informatics Engineering of Aveiro (IEETA)

University of Aveiro

3810-193 Aveiro

Portugal

e-mail: rita.valente@ua.pt

Maria Conceição Costa

Department of Mathematics (DMat) and Centre of Research and Development in Mathematics and Applications (CIDMA)

University of Aveiro

3810-193 Aveiro

Portugal

e-mail: lopescosta@ua.pt

\section{Abstract}

Objectives: To test an alternative Speech and Language Therapy (SLT) service delivery model based on partnerships between a University and local schools and charities, and to report upon the impact and feasibility of intervention based on long-term outcome measures and three case studies with individual analysis of Reliable Change.

Study Design: The following six step model was tested: 1 - Establishing partnerships; 2

- Flagging children; 3 - Pre-treatment SLT assessment; 4 - Reporting and discussion 
Running head: Speech and Language Therapy Service Delivery

with parents and teachers; 5 - Treatment; 6 - Post-treatment assessment. Case studies are presented.

Methods: A partnership was established with one kindergarten in a pre-test and a total of twenty five kindergartens during the second phase of the process. A group of 139 children were then flagged and assessed. The following long-term outcomes (18 months post therapy) were investigated: Phonetic-phonological standardised test percentiles and raw scores; receptive and expressive language percentiles and raw scores according to a standardised language test; percentage of syllables stuttered; duration of stuttering moments; academic achievement in norm-tests' core areas (mathematics, Portuguese language and social studies). Case studies and a 95\% Credible Interval analysis to assess Reliable Change are presented.

Results: Seventy five (54\%) children needed SLT support. Fifty (67\%) of those children returned to the clinic for long-term assessments and the analysis of all outcome measures showed significant improvements in their performance, 18 months posttherapy. Case Studies Reliable Change analysis revealed a statistically significant improvement, which also clearly shows the feasibility and the positive impact of the intervention.

Conclusions: This specialised and differentiated care network constitutes an alternative delivery system of SLT services that addresses the lack of support currently experienced by children and their families. The long-term outcome measures and the $95 \%$ Credible Interval analysis are reliable methods to determine the impact of interventions. Keywords: Service Delivery; Speech and Language Therapy; School-based services; Children 
Running head: Speech and Language Therapy Service Delivery

\section{Introduction}

Speech and Language Disorders have been reported to have a prevalence of $2-25 \%$ in children (Beitchman, Nair, Clegg, \& Patel, 1986; Law, Boyle, Harris, Harkness, \& Nye, 2000; McLeod \& Harrison, 2009; McQuiston \& Kloczko, 2011; Nwosu, 2015;

Pinborough-Zimmerman et al., 2007; Tomblin et al., 1997). These disorders in children can adversely affect emotional, educational and occupational development (Jacoby, Lee, Kummer, \& Levin, 2002). If Speech and Language Therapy (SLT) can be provided at the earliest stage of development then these problems can be more easily remediated (Bryan \& Mackenzie, 2008; Guyer et al., 2009).

However, schools and public services have been facing, over the last years, a loss of funding to support the inclusion of speech and language therapists (SLTs), which has had a negative impact in these services (American Speech-Language-Hearing Association, 2015). Difficult economic times place an exceptional burden on schools and public services to deliver the best education with fewer resources (American Speech-Language-Hearing Association, 2015; Harulow, 2013; Meline et al., 2010). These particular circumstances have a significant impact in small and fragile economies of countries such as Portugal, severely limiting the access to SLT in schools and public services. Currently, SLTs often work with clients/families facing multiple complex communication problems and requiring social assistance who, regardless of their urgent needs, can't have access to support in overcoming difficulties that most likely will create subsequent complications. If SLT intervention is not provided then the risk is that communication difficulties become more severe and pervasive and may require more complex interventions (Bryan \& Mackenzie, 2008). The specific legislation in countries such as Portugal, excludes a considerable number of children that need special support, so it is not possible to give adequate educative responses to these children because of 
Running head: Speech and Language Therapy Service Delivery

legal limitations (Grácio, 2014). This legislation states that children with permanent special needs should have access to adequate educational responses. However, in reality only deaf, blind and autistic children, as well as children with cerebral palsy and other neuro-development disorders, are actually considered (DR, 2008). All the other children that do not have a diagnosis of permanent special need have a reduced chance of support by public services. Children with language, speech and/or communication difficulties are often part of this group that cannot have access to specialised support. Some of these children are treated in private practices but there is large number of parents with economic difficulties that cannot provide their children with much needed care. This lack of support may lead to the accumulation of difficulties (that could be overcome if intervention was given), turning them into chronic alterations, and this can also lead to developmental disadvantage, poor social skills, behavioural problems, emotional difficulties, literacy disadvantage, and mental illness (Bryan \& Mackenzie, 2008; Grácio, 2014). This can also reduce the chance of successful treatment and result in many children not completing or not having treatment before they start school. When this happens, children may access a new learning environment with an undiagnosed and untreated disorder. This often hinders academic performance and educational progression (Jacoby et al., 2002; Willoughby, Chan, \& Marques, 2016).

This calls for new ways of providing support to children that otherwise would not have adequate responses to their problems. A common approach to meet the children's needs has been the provision of treatment by private units associated with mainstream schools (Lindsay, Dockrell, \& Mackie, 2005). To establish new ways of providing support it is important to create a well-structured design scheme. Breaking down service delivery programs structure into their components is very helpful for examining the inputs and resources that are needed to implement them (Mooss, 
Running head: Speech and Language Therapy Service Delivery

Hartman, \& Ibanez, 2015). Alongside this, the opportunity to develop new roles across traditional professional and agency boundaries must be exploited (Gascoigne, 2006). Guidelines for service quality assurance

Children's SLT services should follow specific international guidelines (American Speech-Language-Hearing Association, 2004; CPLOL, 2009; Gascoigne, 2006). The assessments can be conducted in a clinical or educational setting and/or other natural environment conducive to eliciting representative samples of children's speechlanguage and communication abilities. The assessment should be based in standardised and informal tests that allow the evaluation of speech, language, orofacial myofunction and communication. After assessment it is important to produce a report and the resulting information should be conveyed to the Teacher and the caregiver. The report should include screening results, and recommendations, indicating the need for rescreening, assessment, or for a referral (American Speech-Language-Hearing Association, 2004; CPLOL, 2009; Gascoigne, 2006).

After the assessment and report, the next step should be the intervention. The intervention and consultation services should be provided when there is a reasonable expectation of benefit to the child in body structure/function and/or activity/participation and the services should be based on the best available scientific and clinical evidence in conjunction with individual considerations (American SpeechLanguage-Hearing Association, 2004; CPLOL, 2009; Gascoigne, 2006). Treatment may be conducted in a variety of settings, including homes, day care centres, clinics, and schools that are selected on the basis of intervention goals and in consideration of natural contexts for the child (American Speech-Language-Hearing Association, 2004).

The American Speech-Language-Hearing Association (American SpeechLanguage-Hearing Association, 1999) has previously described various options for SLT 
Running head: Speech and Language Therapy Service Delivery

service delivery methods being the pull-out method the most prevalent option: Children are provided with one-to-one or a small group therapy sessions in an independent room environment (American Speech-Language-Hearing Association, 2008; Mcginty \& Justice, 2006; Throneburg, Calvert, Sturm, Paramboukas, \& Paul, 2000; Wilcox, Kouri, \& Caswell, 1991). The caregivers should be encouraged to be present during intervention sessions because training of others, including parents, should be viewed as a central activity for SLTs to maximise the impact to the child and his/her family (Gascoigne, 2006).

In any setting, intervention should be family-centred, developmentally supportive, culturally appropriate and should address the personal and environmental factors that are barriers to or facilitators of children's communication (American Speech-Language-Hearing Association, 2004; Gascoigne, 2006; World Health Organization, 2001).

Follow-up procedures are used to complete or supplement an assessment, monitor progress during intervention, and/or determine status after screening, assessment, intervention, or discharge (American Speech-Language-Hearing Association, 2004).

The best practices described above should be the basis of a service delivery model, so it is very important to ensure that the right resources and conditions are in place when implementing these practices. This can be found at the University of Aveiro (UA), in Portugal, where an alternative SLT service delivery model has been developed, to overcome a generalised limited provision for children. At the UA, parents and teachers find a specialised team of SLTs that can cover a wide range areas. This team is able to provide care based on current best clinical practice guidelines. Furthermore, the clinic at the Speech, Language and Hearing Laboratory (SLHlab), is very well adapted 
Running head: Speech and Language Therapy Service Delivery

to SLTs', audiologists', psychologists', parents' and children's needs, which facilitates assessment and treatment. This represents an added value and has allowed clinicians to support local children that would not have access to SLT treatment in other way.

Unfortunately, there are no program delivery guidelines for organising or implementing speech-language and hearing services (Meline et al., 2010). The aim of this paper is to explore and provide new insights into the possibility of constructing an alternative delivery system of SLT services to address the problem presented above and to discuss how to ensure the best practices. We present here an approach that was able to respond to the needs of children as an alternative service delivery model based in partnerships between the UA and local schools. This model intends to be an alternative to the lack of support experienced by the children with language, speech and/or communication disorders (children without permanent special needs) that were not covered by public legislation as priorities for service delivery. The paper first describes the methodology used to establish a new way of providing SLT support to children in pre-school and school aged children. The percentage of children flagged and in need of support, long-term outcomes designed to reveal if the therapy delivered has lasting effects and three case studies are presented and discussed. These three case studies are representative of the main intervention areas that had a major incidence in this sample. Case studies allow a careful and detailed observation, they are suitable for preliminary research and during the development of new assessment and intervention programs (Morgan \& R, 2009). Case studies present a great value because many communication disorders are heterogeneous in nature (Ferguson \& Armstrong, 2009).

In general, case studies present several advantages as close observation of individual changes over time, are cost-effective and positive results are enough to guarantee the need for more experimental investigation with larger samples (Unicomb, 
Running head: Speech and Language Therapy Service Delivery

Colyvas, Harrison, \& Hewat, 2016). However analysis of case studies commonly relies on visualising some aspects of the data and formal statistical approaches (normally relying on the use of continuous data) may not be the best option in these cases. Case study designs can be criticised for being less rigorous and statistical robust (Yin, 2009). The determination of statistically significant change in outcome measures is thus very important for research. One method of measuring the statistical significance of individual change is to analyse the 95\% Credible Intervals (CI) (Unicomb et al., 2016) as used in this study.

Aims

This study aims to present and describe a methodology of SLT service delivery to diminish the gap between the number of children in need of support and the number of children that actually receive this support. This methodology was implemented in Portugal but the same gap between the number of children in need and children receiving support is experienced in many other countries.

\section{Method}

The study was carried out at the University of Aveiro in Portugal. It was developed as part of a project where digital materials for SLTs to work with children with Speech Sound Disorders (SSD) were validated (Jesus, Martinez, Santos, \& Joffe, 2016a, 2016b; Jesus, Santos, Martinez, Lousada, \& Pape, 2015). This project's team included a Speech and Language Therapist that was able to implement the method described below. Furthermore, another Speech and Language Therapist (a funded Ph.D. student) also participated in the provision of services. This fact allowed the implementation of a free support system for children and for kindergartens/schools. This service targeted mainly children in pre-school and primary school age (with some exceptions regarding children and adolescents referred by external SLTs). To our best knowledge, there is no similar 
Running head: Speech and Language Therapy Service Delivery

service delivery established between a university, with a SLT team with different specialisation areas, and schools in Portugal, where children with speech and language difficulties could benefit from free therapy; for that reason, outcomes need to be analysed in order to assess the feasibility of the proposed service delivery model. Those outcomes and conclusions could be widespread, to support a similar implementation, financed by regional administrations.

This service delivery incorporated the six step procedure described in Figure 1, based on the best practices described above.

Please insert Figure 1 about here

\section{Establishing partnerships}

The first step to establish partnerships was to identify the schools and institutions in the Aveiro region that could benefit from SLT support. A list of contacts of every school and institution that did not have internal SLTs or that was not covered by national public services was made. A total of 30 schools were contacted and a meeting was held (where the Project was explained) with the heads of institutions that replied (a total of 25). The project had good acceptability; All the schools and institutions that replied to the first contact established by the research team accepted to participate and showed enthusiasm regarding the project mainly because this was the only way that some children (with economic difficulties) could have free support. After the first meeting the research team started the project implementation that included a second meeting with the teachers to explain the project in more detail and directly to them, to answer questions and to ask them to flag the children that they thought presented difficulties in speech perception/production and language development. 
Running head: Speech and Language Therapy Service Delivery

\section{Flagging children}

During the initial meeting, the research team provided the teachers with information related to normal linguistic development and characteristics of communication impairments. The school teachers were asked to flag any child that they considered as being in need of SLT support, based on the information gathered on the initial meeting. After the identification of the children, an Informed Consent was sent to the parents of the flagged children. If the parents consented, it was handed back to the school teachers that forwarded them to the research team. Although the main way of flagging was by the process described above, some children reached the service by flagging of external SLTs and parents.

\section{Assessment}

Every flagged child was then assessed by a certified Speech and Language Therapist, at three specific time-points: Pre-intervention, one week post-intervention (reported in case-studies) and eighteen months post-intervention (reported for all of those children that returned to the clinic for post-intervention long-term assessments). The assessments were based in standardised and informal tests that allowed the evaluation of speech, language, orofacial myofunction, fluency and communication according to the needs of the child flagged. Related to language, the TL-ALPE (Mendes, Afonso, Lousada, \& Andrade, 2014; Mendes, Lousada, Valente, \& Hall, 2014), a norm-referenced instrument, was used to assess the comprehensive and oral expressive language (semantics and morphosyntax). The TL-ALPE presents content validity, construct validity, criterion validity and inter- and intra-judge reliability. The TFF-ALPE (Lousada, Mendes, Valente, \& Hall, 2012; Mendes, Afonso, Lousada, \& Andrade, 2013b) was the norm-referenced test used to assess the verbal articulation and type and 
Running head: Speech and Language Therapy Service Delivery

percentage of occurrence of phonological processes. Inter- and intra-judge validity, content and construct validity were assured. To assess the oro-motor function of face, lips, jaw, teeth, tongue and palate, the PAOF test (Guimarães, 1995) was used. Related to fluency, spontaneous speech samples were collected and assessed in terms of stuttering severity. Additionally, the impact of stuttering in quality of life was assessed through the administration of the Overall Assessment of the Speaker's Experience of Stuttering (OASES) questionnaire (Yaruss \& Quesal, 2006).

The assessment process was audio-recorded using a Behringer ECM8000 microphone located 1 meter from the mouth of the children. The microphone was connected to an Olympus LS-100 recorder. The assessments took place in two distinct environments: The SLHlab clinic at the UA; the children's schools. Children were diagnosed based on several parameters. For Speech Sound Disorders (SSD), inclusion criteria were: No alterations on oro-motor structure and function (assessed with the PAOF (Guimarães, 1995); no symptoms of verbal dyspraxia; normal receptive language assessed with the TL-ALPE (Mendes, Afonso, et al., 2014); presenting at least two phonological processes (Crosbie, Holm, \& Dodd, 2005; Dodd, Zhu, Crosbie, Holm, \& Ozanne, 2002). Children were diagnosed with Developmental Language Disorder (DLD) if language scores were below -1.5 SD the mean of TL-ALPE and in the absence of another condition such as hearing impairment, emotional or behavioural difficulties, autism, neurological impairment or general developmental difficulties. Children with Fluency Disorders (FD) were signalled when they presented a minimum frequency of stuttering-like disfluencies (i.e., sounds, syllables or one syllable words repetition; prolongations of sounds or blocks of airflow or voicing in speech) of 3 per 100 syllables; greater than average duration, effort and tension of stuttering-like disfluencies and concerned about fluency disruption (Yairi \& Ambrose, 2005). 
Running head: Speech and Language Therapy Service Delivery

In addition to the assessment instruments described above, which are specific to the field of SLT, the two SLTs also collected information concerning academic activities. Academic activities should be part of a comprehensive assessment and refer to general school experiences. Data collected at school settings provide data that are useful to analyse functional communication abilities. The collection of information concerning academic activities could be made through systematic observation (i.e., observation of school performance) or measurement (i.e., school performance or academic achievement in norm-tests). In the therapy delivery service implemented, the SLTs collected data through systematic observation of children's speech and language during oral activities in school environment, kindergarten teachers' feedback and academic achievement in norm-tests for those children in primary school at 18 months post-therapy. In Portuguese primary schools, academic achievement is assessed in three core areas (mathematics, primary language and social studies) and results reported using the following assignment of test scores to qualitative descriptors: 0-49\% not good enough (insuficiente); 50-69\% good enough (suficiente); 70-89\% good (bom); 90-100\% very good (muito bom).

All participants in this study were in kindergarten at pre-intervention assessment, where, in Portugal, academic achievement is not assessed with norm-tests. We therefore only presented academic results for children that were enrolled in primary school at the time of assessment.

\section{Reporting and discussion with caregivers and teachers}

After the SLT assessment a report was made for each child and the results were communicated to the teachers and parents/caregivers. The report included screening results and recommendations, indicating the need for rescreening, assessment, or for a referral. Children were excluded from the study if they presented an adequate linguistic 
Running head: Speech and Language Therapy Service Delivery

development for their age group or referred to SLT treatment if they presented alterations that were inclusion criteria for any of the communication disorders referred above.

\section{Treatment and post-treatment assessment}

After the report given to caregivers and teachers 75 children benefited from individualised intervention services that were provided at the clinic or their schools when they were not able to travel to the clinic. The children were provided with one-toone therapy sessions in an independent room environment. When possible, the caregivers were encouraged to be present during the intervention. Due to the complexity of each disorder and the variability within each children the intervention procedures must comprise different intervention methods in order to fully respond to the children's needs. Therefore the intervention strategies were based on several evidence-based approaches.

Concerning SSD intervention, a phonologically based intervention was used. It consisted of a combination of phonological awareness activities (Lousada et al., 2013) adapted from Gillon and McNeill's (2007) phonological awareness programme, as well as Hodson \& Paden's (1991) auditory bombardment and discrimination and listening tasks from Lancaster (2008).

Related to DLD, several forms of a hybrid approach were used, that is, specific language goals were considered for intervention, based on the assessment process. The activities and materials were selected by the clinician to consciously elicit the spontaneous use of the language skills targeted by the intervention plan objectives (Paul \& Norbury, 2012). General methods of modelling, imitation and reinforcement to develop learning and language skills were also used (Owens, 2011; Paul \& Norbury, 
Running head: Speech and Language Therapy Service Delivery

2012). Related to intervention on stuttering, the eclectic methodology approach developed by Guitar (2014) was used. Identification, desensitisation, learning of fluency skills and generalisation were the phases of the intervention approach used (Guitar, 2014).

After a period of intervention, a short-term follow-up assessment (one week post-intervention) was performed to monitor progress and to determine the need of further treatment or discharge. All 75 children that benefited from individualised intervention were targeted for a long-term follow-up assessment eighteen months postintervention. Two certified SLTs, blind to the purposes of the study, were involved. They first contacted the caregiver to schedule an assessment session. During the followup session, the assessment procedures and instruments applied were similar to those used in the pre-treatment session, and included (when available) the collection of information related to academic progress and achievements.

More specifically, the following long-term outcomes were investigated: Phonetic-phonological standardised test percentiles and raw scores; receptive and expressive language percentiles and raw scores according to a standardised language test; percentage of syllables stuttered; duration of stuttering moments; academic achievement in norm-tests' core areas (mathematics, Portuguese language and social studies). For comparison purposes, during post-intervention assessment, children who were above the maximum age-band (only $26 \%$ of the total number of children) on both the TFF-ALPE and TL-ALPE, were compared with the maximum age-band available. Therefore, raw score data for the TFF-ALPE phonetic/production subtest were also provided for reference. 
Running head: Speech and Language Therapy Service Delivery

IBM SPSS Statistics 22 was used to perform a non-parametric paired sample analysis through the Wilcoxon signed ranks test in order to compare several long-term outcomes before and after the intervention considered in this paper.

A pre-test of this model was conducted in one kindergarten. The methodology used were similar to those presented on each phase. It was concluded that the methodology was feasible to be generalised to a larger sample of 25 schools and kindergartens in the Aveiro region.

\section{Case Studies}

The case studies represent "an empirical enquiry that investigates a contemporary phenomenon in-depth and within its real-life context" (Yin, 2009). In the three cases a summary of the patient clinical history and referral process, the assessment procedures, the setting where the intervention took place, details about the intervention and the patients progress based on pre- and post-intervention outcome measures, are presented. The first case study refers to a child with SSD, where an intervention based on phonological awareness activities was employed. The second case study refers to a child with DLD and the third case study describes an intervention with an adolescent who stutters. Those individuals were chosen since they represent the three main intervention groups in the sample, i.e. SSD, DLD and FD. The presented cases were select using a random procedure within each group. The outcome measures are specific to each case study.

\section{5\% Credible Intervals}

To address whether the observed changes in the case studies presented can be considered statistically significant (i.e., whether the intervention provided using this service delivery program was effective), the $95 \%$ Credible Intervals (CI) for the difference in proportions 
Running head: Speech and Language Therapy Service Delivery

were constructed according to the methodology described in Unicomb et al. (Unicomb et al., 2016). The binomial distribution was taken as the underlying statistical model as it is a discrete distribution that is applicable whenever a fixed number of trials, $n$, is considered, for which there are only two possible outcomes: The success with probability $p$ and the failure with probability 1-p. The trials are independent of each other and one is focused in counting the number of successful events in the total number of trials. In case study 1 (SSD), for instance, $n$ represents the total number of consonants, $x$ is the number of correct consonants and $p=x / n$ is the proportion of correct consonants. With the $95 \% \mathrm{CI}$ for the difference in two proportions it is possible to test if the difference between pre and post treatment scores can be considered statistically significant. The same pre and post treatment analysis can be established for case studies $2(D L D)$ and $3(S D)$ where the outcome measures are also binary categories and the binomial distribution is applicable.

The $95 \%$ CI for the difference in pre and post treatment proportions were constructed according to the Bayesian approach proposed in Agresti and Min (2005). These authors refer to the $95 \%$ CI for the difference as Bayesian confidence intervals because a $100(1-\alpha) \%$ interval is obtained for a parameter, choosing the $100(\alpha / 2) \%$ and $100(1-\alpha / 2) \%$ percentiles of the posterior distribution for the parameter. In this sense a Bayesian confidence interval is a region that has posterior probability equal to the desired confidence level. The values for the posterior distribution were randomly generated using Markov Chain Monte Carlo methods. All computations were done with the free software $\mathrm{R}$ version 3.3.1., using the code provided by Unicomb et al. (2016).

To ascertain whether the difference between each individual in the case studies' pre and post treatment scores is statistically significant, one has to inspect the $95 \%$ CI for the difference and see if the interval does not contain the zero value. If it doesn't, then there has been a reliable change at the 0.05 significance level. To visually assess 
Running head: Speech and Language Therapy Service Delivery

significance the credible intervals were plotted using Microsoft Excel 2013. For each case study a scatter plot was created representing pre and post treatment proportions against each other, together with a reference line of no change. Data points thus represent pre and post treatment proportions for each individual in each case study. The upper and lower $95 \%$ CI were used to draw the error bars to visually ascertain the level of uncertainty in the difference in pre and post treatment proportions.

\section{Results}

\section{Service Delivery}

During the pretest phase of the project, the teachers from one kindergarten (Jardim de Infância de Santiago in Aveiro) flagged twenty children (20\% of the total number of children in that particular kindergarten), with eleven $(11 / 20=55 \%)$ children needing intervention and nine $(9 / 20=45 \%)$ not presenting relevant alterations for their age. These nine children showed signs that were deviant from normal development but did not need/justify SLT support, e.g., some children presented phonological processes but these were considered normal for their age group. All teachers and parents reviewed (with the Speech and Language Therapist) their children's individual reports. Two additional cases from this kindergarten were referred to the UA team by external SLTs and parents. The majority of the children in need of SLT had speech and/or language disorders, having then access to intervention based on proven methodologies according to their needs.

In the larger study, the research team established partnerships with a group of 25 kindergartens and schools from the Aveiro region. In this second stage of the project, a group of 128 children were flagged by their teachers. In addition, a group of 11 children were referred by external SLTs and parents mainly due to the specific expertise of the 
Running head: Speech and Language Therapy Service Delivery

SLT team and mouth-to-mouth publicity about the service creation. The total number of children included in the larger study group was 139 , as shown in Figure 2.

Please insert Figure 2 about here

The flagged children were assessed by a team of two SLTs. As seen in Figure 2, from the 139 children flagged, 46\% (64 children) did not present relevant alterations for age, but still a report was made and shared with teachers and parents. The other 54\% (75 children) needed SLT and the most common alterations in this group of children were SSD, DLD and FD. From the 75 children that presented alterations, 42 children presented SSD, 20 had DLD and 13 had FD.

The results of the flagging processes were in line with screening literature that points a much less accurate estimate of children development when non formal screening is used (Sandler et al., 2001).

In general, the kindergarten teachers and/or parents reported that children had a low participation and difficulties in social communication and integration with peers.

When needed, children were also evaluated by an Audiologist, and by a Psychologist to assess their non-verbal IQ. These assessments were possible due to the wide network of health professionals working within the UA.

After the initial assessment, children entered an intervention program, delivered by the same team of two SLTs. Concerning children with SSD, the average number of intervention sessions were twelve, consisting of a phonological based intervention. Each session had an average duration of 45 minutes; at the end of each session the Speech and Language Therapist provided recommendations to parents or kindergarten teachers 
Running head: Speech and Language Therapy Service Delivery

on how to potentiate the benefits of the therapeutic intervention (e.g., through homework). The specific goals for intervention in children with DLD were reached after an average of twenty sessions with a mean duration of 45 minutes each. The parents were encouraged to participate in every therapeutic session, in order to maximise the therapeutic gains. The stuttering intervention processes consisted of four phases, with an average of four sessions per phase. Specifically, related to children who stutter, family interaction patterns were also the focus of intervention in order to facilitate the child's fluency. Teachers and classroom peers were also involved in the treatment program to raise awareness towards stuttering.

Long-term post-intervention assessment was used to monitor their progress in several aspects, including speech and language skills and academic activities.

Concerning children with SSD, the percentage of return to assessment 18 months post-intervention was $76 \%(32 / 42)$, with a mean age of 57 months (stdev $=10$ months) before intervention start. TFF-ALPE Phonetic subtest mean percentiles were pre $5.9($ stdev $=4.0)$ and post $31.9($ stdev $=19.9)$; TFF-ALPE Phonological subtest mean percentiles were pre $5.0(\operatorname{stdev}=3.4)$ and post $31.9($ stdev $=14.8)$; TTF-ALPE Phonetic subtest mean raw scores were pre $49 / 90=54 \%($ stdev $=10 \%)$ and post $77 / 90$ $=86 \%(\operatorname{stdev}=10 \%)$.

In order to compare the children's performance before and after the intervention period, the Wilcoxon signed ranks (unilateral) test was used for all the variables considered. Regarding the percentiles of the TFF-ALPE phonetic and phonological subtests, the non-parametric approach was used since the Normality tests rejected the null hypothesis of a Normal population. In all other cases (DLD and FD groups) the non-parametric test was used due to the small sample sizes (DLD $-\mathrm{N}=10 ; \mathrm{FD}-\mathrm{N}=7$ ). 
Running head: Speech and Language Therapy Service Delivery

Significant differences between pre and post percentiles of the TFF-ALPE phonetic and phonological subtests were found $(Z=-4.937, p=0.000$, effect size $=0.62$ (large effect) for both the phonetic and phonological subtests). Note that although this study did not include a control group, the natural evolution of the children is taken into account since the percentiles were calculated considering the age group. Typically developing children mature naturally and the percentiles described in TFF-ALPE incorporate this evolution (each child will tend to keep his percentile along time). Comparing percentiles from pre to post-intervention moments can be used to detect a non-typical progress in the children's development.

Post-intervention academic achievement of the 18 children with SSD that were enrolled in primary school was quite satisfactory: Only one child was qualified as not performing "good enough" (insuficiente); $33 \%$ of the children in mathematics, $28 \%$ in Portuguese language and 50\% in social studies were classified as "very good" (muito bom).

Ten children (50\%) with DLD returned to long-term assessment, with a mean age of 55 months (stdev $=8$ months) before intervention start. TL-ALPE mean receptive language percentiles were pre $19.7(\mathrm{stdev}=12.4)$ and post $46.7(\mathrm{stdev}=18.4)$; TL-ALPE mean expressive language percentiles were pre $9.0(\mathrm{stdev}=7.0)$ and post $34.5($ stdev $=13.6)$; TL-ALPE mean receptive language raw scores were pre 34/49= $70 \%(\operatorname{stdev}=9 \%)$ and post $43 / 49=87 \%(\operatorname{stdev}=5 \%)$; TL-ALPE mean expressive language raw scores were pre $34 / 76=45 \%(\operatorname{stdev}=9 \%)$ and post $53 / 76=70 \%($ stdev $=$ $6 \%)$.

Regarding the percentiles of the TL-ALPE receptive and expressive subtests, significant differences were also found between the pre and post-intervention values $(Z=-2.803, p=0.001$, effect size $=0.63$ (large effect) for both the receptive and 
Running head: Speech and Language Therapy Service Delivery

expressive subtests). As for the TFF-ALPE, the natural evolution of the children's performance is taken into account by the fact that we are comparing percentiles, calculated for the appropriate age-group at each moment.

Only three out of ten children with DLD assessed at 18 months post-intervention were enrolled in primary school but all with "good enough" (suficiente) to "very good" (muito bom) performance in all areas.

Results from the pre-intervention assessment of children who stutter (CWS) revealed a mean percentage of stuttered syllables of $8.3 \%(\operatorname{stdev}=2.2 \%)$ and the presence of associated behaviours, mainly nonverbal (i.e., extremities movements). Mean duration of stuttering moments were $2.9 \mathrm{~s}(\mathrm{stdev}=1.0 \mathrm{~s})$. Feedback collected from teachers and parents revealed a low impact on academic achievements. However, one child stood out on their participation levels at school, due to the avoidance of communication moments. Some negative results were observed in measures of academic achievement that could be attributable to the stuttering impact. Eight out of the thirteen (67\%) CWS returned to post-intervention. All children presented less than $1 \%$ of stuttered syllables $($ mean $=0.6 \%$; stdev $=0.2 \%)$, a mean duration of stuttering moments lower than $2.0 \mathrm{~s}($ mean $=1.9 \mathrm{~s} ; \mathrm{stdev}=1.0 \mathrm{~s})$ and absence of associated behaviours at 18 months post intervention. Feedback from teachers revealed that academic achievements were no longer impacted by the FD and that an improvement was observed on fluency during speech activities (e.g., when describing, in class, their weekend activities or vacations), mainly on one children that presented avoidance on classroom participation prior to fluency intervention. The children that did not return to the long-term follow-up (eighteen months post intervention) presented a low value (less than $1 \%$ ) of stuttered syllables at the end of service delivery (one week post intervention). 
Running head: Speech and Language Therapy Service Delivery

Finally, both the percentage of stuttered syllables and the duration of stuttering moments also showed significant differences from pre to post-intervention $(Z=-2.366$, $p=0.008$, effect size $=0.63$ (large effect) for both variables).

In spite of the small sample size considered in the last two analysis performed $(\mathrm{N}=10$ and $\mathrm{N}=7)$, the statistical tests and the large effect sizes obtained suggest that the intervention produced effective changes in the children's performance that would not have been achieved without it.

\section{Case Studies}

The three case studies represent areas (SSD; DLD; FD) that are very common in the SLT clinic. Participants selected as case studies were randomly selected.

For the SSD client percentage of correct consonant and phonetic inventory are presented and for the child with DLD the results of a standardised pre-school language test are reported. For the FD client the results are presented in terms of percentage of syllable stuttered and the global impact in quality of life.

Speech Sound Disorders (SSD) - Case Study 1

Participant: DB, a 4;1 year old male, was referred by his kindergarten teacher due to his low intelligibility of speech. Assessment: He was assessed in June 2015. Data related to the case history, collected using University of Aveiro's Case History Form for Child Language (Jesus \& Lousada, 2010), showed no relevant alterations. Further assessment included a phonetic-phonological test - TFF-ALPE (Mendes, Afonso, Lousada, \& Andrade, 2013a); a language test - TL-ALPE (Mendes, Afonso, et al., 2014) and an oromotor abilities test - PAOF (Guimarães, 1995). He showed normal expressive and receptive language for age and did not present oro-motor alterations. The child was also assessed by a Psychologist and an Audiologist to establish the diagnosis of SSD (with normal non-verbal IQ and normal hearing). Setting: A pull-out method was used and the 
Running head: Speech and Language Therapy Service Delivery

child had one-to-one therapy sessions in SLHlab's clinical setting and the caregiver (mother) participated in all sessions (in some session his older brother was also present). Intervention: He then had 12 sessions of phonological based intervention (Jesus et al., 2016a) centred in well-known methodologies (Gillon \& McNeill, 2007; Hodson \& Paden, 1991; Lancaster, 2008; Lousada et al., 2013). The main phonological process targeted was the stopping of fricatives. Progress: DB presented a Percentage of Consonants Correct (PCC) of $56 \%$ at pre intervention that positively evolved to $76 \%$ after intervention. Results presented in Figure 3 revealed that the change between pre and post intervention is statistically significant because the $95 \%$ CI bars do not cross the reference line. He added to his phonetic inventory the sounds [f, v, s, $\left.z, \int, 3, \mathrm{n}, \mathrm{R}\right]$. An increase in his intelligibility was noticed and reported by his parents, teacher and peers.

Please insert Figure 3 about here

\section{Developmental Language Disorder (DLD) - Case study 2}

Participant: TC, a 3;11 year old male, was flagged by his kindergarten teacher due to low expressive skills in comparison to his peers. Assessment: TC was assessed in September 2015. University of Aveiro's Case History Form for Child Language (Jesus

\& Lousada, 2010) was used, revealing no alterations from normal development. Further assessment also included: A phonetic-phonological test - TFF-ALPE (Mendes et al., 2013a); a language test - TL-ALPE (Mendes, Afonso, et al., 2014) and an oro-motor abilities test - PAOF (Guimarães, 1995). He showed alterations in receptive and expressive skills on the language test, on the phonetic-phonological test but no relevant alterations in oro-motor abilities. Setting: A pull-out method was used and he had oneto-one therapy sessions in SLHlab's clinical setting and the caregiver (grandmother) 
Running head: Speech and Language Therapy Service Delivery

was present in all sessions. Intervention: Language intervention (Owens, 2011; Paul \& Norbury, 2012) over 20 sessions was then provided to the child. Progress: Initially, the child showed very low communicative intent, preferring gestures rather than words. He was at Percentile 14 in expressive language and Percentile 5 in receptive language according to the TL-ALPE language test. TC presented a total of 32 correct answers in 76 possible for expressive language and a total of 30 correct answers in 49 possible regarding receptive language. After intervention he improved his communicative intent, started to use more words than gestures and the language test scores evolved positively to Percentile 23 in expressive language and Percentile 84 in receptive language. He presented a total of 40 correct answers in 76 possible for expressive language and a total of 45 correct answers in 49 possible for the receptive language. Results presented in Figure 4 revealed that the change between pre and post intervention is not statistically significant for expressive language, because the $95 \%$ CI bars cross the reference line. Figure 5 shows that the change between pre and post intervention is statistically significant for receptive language because the $95 \%$ CI bars do not cross the reference line.

Please insert figures 4 and 5 about here

Fluency Disorders (FD) - Case Study 3

Participant: DV, a 17 year old adolescent client who stutters was referred by an external Speech and Language Therapist due to the fact that one of the team's SLTs has a clinical specialisation in FD. Assessment: DV was assessed in October 2015. Data related to the case history was collected using the "Stuttering Case History Form Adolescent/Adult" (Guitar, 2014). In order to obtain a holistic comprehension of DV as 
Running head: Speech and Language Therapy Service Delivery

a person who stutters, several methods were implemented during the assessment:

Collection of three different speech samples (to assess stuttering severity) and administration of the Overall Assessment of the Speaker's Experience of Stuttering (OASES) questionnaire (Yaruss \& Quesal, 2006), to assess the impact of stuttering in DV's quality of life. Setting: A pull-out method was used and DV had one-to-one therapy sessions in SLHlab's clinical setting. Intervention: During 14 intervention sessions with DV, the integrated approach of Guitar (Guitar, 2014) was followed. Progress: Initially DV presented a frequency of $3.4 \%$ of stuttered syllables, with a mean duration of $0.7 \mathrm{~s}$ and barely noticeable physical concomitants. The client presented mainly repetitions and audible prolongations. It was concluded that stuttering presented a moderate impact on DV. Post-assessment revealed that percentage of syllable stuttered $(\% \mathrm{SS})$ decreased to $1.5 \%$ as well as the impact of stuttering on communication in daily situations and quality of life. Figure 6 shows that the change between pre and post intervention is not statistically significant because the 95\% CI bars cross the reference line.

Please insert Figure 6 about here

\section{Discussion}

Results showed that the proposed service delivery model can facilitate the detection of children in need of SLT in preschool and primary school years that do not have access to adequate support at the moment. When young children start school with speech, language and/or communication needs they carry a greater risk of developing problems in literacy and numeracy learning (Botting, Simkin, \& Conti-Ramsden, 2006; Brown et al., 2015; Gardner, Froud, McClelland, \& Lely, 2006; Guyer et al., 2009; Snowling, 
Running head: Speech and Language Therapy Service Delivery

John, Bishop, \& Stothard, 2001). If language difficulties are resolved early and oral skills continue to improve at the same rate with development, then school performance will be within the normal range (Snowling et al., 2001).

As the number of children that start school with speech, language and/or communication need is higher than what it is recommended due to cuts that schools are facing (BE, 2016; DE, 2012; DN, 2016; Rosa, 2013, 2016), an increasing number of children is advancing in their school path with impairments that will affect their progression in personal and educational life. This will have an impact in their emotional, occupational and educational development that influences the children's quality of life. Early identification and intervention, through a feasible service delivery model may have a role in decreasing the risk of developing secondary disabilities and in reducing the economic burden of communicative impairments in society (Popova, Lange, Burd, Shield, \& Rehm, 2014).

It was observed that teachers were aware of children's speech and language alterations, resulting in more than half of the children flagged having relevant alterations and being in need of immediate support. Even the $46 \%$ that didn't have relevant alterations for their age showed some signs that were deviant from normal development, but not sufficient to need support, i.e., they showed, for example, some phonological processes in their speech that were not present in most of their peers but these processes were considered normal for age. Some kindergarten teachers flagged these children because they were not sure if these alterations were normal or not. However, the accuracy of the flagging of children by teachers can still be increased if workshops and awareness campaigns are promoted in schools. 
Running head: Speech and Language Therapy Service Delivery

Early identification and access to high quality services may have a role in decreasing the risk of developing secondary disabilities and in reducing the economic burden of communicative impairments in society (Popova et al., 2014).

The long-term outcomes investigated, reveal that the therapy delivered, appeared to have lasting effects. This has implications for Speech and Language Therapy including reduced therapy times and defining a set of core outcomes.

This impact was also exemplified for our service delivery model in the case studies (a similar analysis was implemented for all the cases treated within the project). Regarding Case Study 1 and Case Study 2 - Receptive language, the 95\% CI for the difference in pre and post intervention scores was $[10.15 ; 28.48]$ and $[13.79 ; 44.86]$ respectively. These ranges do not include the zero value, which means that the increase in PCC and correct answers in the receptive language test are statistically significant. For Case Study 1 this result means that DB increased his correct production of consonants after intervention. For Case Study 2, the results showed that the intervention contributed to a significant increase in TC's number of correct answers which means that he improved his receptive language capacities.

In terms of Case Study 2 - Expressive Language and Case Study 3 the 95\% CI for the difference in pre and post intervention proportions was $[-5.33 ; 25.60]$ and $[-4.03$; 0.03 ] respectively. Both ranges include the zero value meaning that the change was not statistically significant. Regarding Case Study 2 the result was expected because the intervention focus was only on receptive language. In spite of the non-significance of change, TC showed some positive progress probably due to an indirect impact of the receptive language intervention. For Case Study 3 the results reveal some decrease in the $\% \mathrm{SS}$; however as the $\% \mathrm{SS}$ in the first assessment moment was per se very low it 
Running head: Speech and Language Therapy Service Delivery

would be difficult to expect a larger change. Qualitatively, the intervention had a greater impact regarding DV's quality of life and attitude towards stuttering.

\section{Conclusions}

This specialised and differentiated care network can constitute an alternative delivery system of SLT services that address the lack of support experienced currently, meeting children's needs and minimising the burden of communication disorders. It is very likely that this will have an impact in literacy, reading and writing acquisition, promoting positive school outcomes that contribute to a better quality of life in children.

It would be interesting to analyse this impact in a future longitudinal study assessing the children that participated and had intervention. Also an implementation of this model in a permanent way could benefit more children every year and contribute to close the gap between the number of children needing support and the ones that can have access to it.

The use of the $95 \%$ Credible Interval analysis proved to be suitable for assessing the change in the used measures allowing the illustration of the impact of the intervention in the three case studies presented.

This model can be seen as an alternative way of responding to the needs of children that are lacking support. In general, it can be concluded that the model can contribute to an increase in the quality of life of the treated children that otherwise would have no access to SLT support. The interventions were always based in wellknown methodologies that had been shown previously to be effective. The implementation model can be seen as an available resource that allows the creation of links between kindergartens, schools and clinical population. 
Running head: Speech and Language Therapy Service Delivery

As future work more research on how teacher oriented workshops and awareness campaigns influence the accuracy of the flagging is suggested. It would also be interesting to explore the impact of this service delivery on later literacy acquisition.

\section{Acknowledgments}

This project has been partially funded by Calouste Gulbenkian Foundation, Portugal. The authors would like to thank all children, parents, kindergartens and schools that participated. The authors would also like to thank Andreia Hall, Isabel Monteiro da Costa and Joana Alves.

\section{Author Statements}

Ethical approval was obtained from all authorities required by Portuguese bylaws for clinical and educational research: National data protection committee; independent ethics committee; Ministry of Education. Authorisation and informed consent was collected from all carers prior to any data collection. The authors have no competing interests. 
Running head: Speech and Language Therapy Service Delivery

\section{References}

Agresti, A., \& Min, Y. (2005). Frequentist Performance of Bayesian Confidence Intervals for Comparing Proportions in $2 \times 2$ Contingency Tables, 61, 515-523. http://doi.org/10.1111/j.1541-0420.2005.031228.x

American Speech-Language-Hearing Association. (1999). Guidelines fo the Roles and Responsibilities of the School Based Speech-Language Pathologist.

American Speech-Language-Hearing Association. (2004). Preferred Practice Patterns for the Profession of Speech-Language Pathology [Preferred Practice Patterns]. http://doi.org/10.1044/policy.PP2004-00191

American Speech-Language-Hearing Association. (2008). 2008 schools survey: Caseload characteristics. Rockville: MD: Author.

American Speech-Language-Hearing Association. (2015). Budget Cuts: Maintaining Speech-Language Pathology and Audiology Services in Schools.

BE. (2016). Diminuição do número de alunos por turma e promoção do sucesso escolar (projeto de resolução no 181/XIII/1ª). Bloco de Esquerda (BE), Lisboa, Portugal.

Beitchman, J., Nair, R., Clegg, M., \& Patel, P. (1986). Prevalence of speech and language disorders in 5-year-old kindergarten children in the Ottawa-Carleton region. Journal of Speech and Hearing Disorders, 51, 98-110.

Botting, N., Simkin, Z., \& Conti-Ramsden, G. (2006). Associated reading skills in children with a history of specific language impairment (SLI). Reading and Writing, 19, 77-98.

Brown, C. M., Beck, A. F., Steuerwald, W., Alexander, E., Samaan, Z. M., Kahn, R. S., \& Mansour, M. (2015). Narrowing Care Gaps for Early Language Delay : A Quality Improvement Study. Clinical Pediatrics, 1-8. http://doi.org/10.1177/0009922815587090 
Running head: Speech and Language Therapy Service Delivery

Bryan, K., \& Mackenzie, J. (2008). Meeting the speech language and communication needs of vulnerable young people - Model of service delivery for those at risk of offending and re-offending. London.

CPLOL. (2009). A framework for ethical practice in Speech and Language Therapy. Turin.

Crosbie, S., Holm, A., \& Dodd, B. (2005). Intervention for children with severe speech disorder: A comparison of two approaches. International Journal of Language \& Communication Disorders, 40(4), 467-491.

DE. (2012). Educação sofre o maior corte desde o 25 de Abril. Diário Económico (DE), 5/4/2012, Lisboa, Portugal.

DN. (2016). BE quer repor apoio de Educação Especial para milhares de alunos. Diário de Notícias (DN), 18/2/2016, Lisboa, Portugal.

Dodd, B., Zhu, H., Crosbie, S., Holm, A., \& Ozanne, A. (2002). Diagnostic Evaluation of Articulation and Phonology. London: Psychological Corporation.

DR. (2008). Ministério da Educação: Decreto de Lei 3/2008. Diário Da República, 1(4), $154-164$.

Ferguson, A., \& Armstrong, E. (2009). Researching communication disorders. New York: Palgrave Macmillan.

Gardner, H., Froud, A., McClelland, A., \& Lely, H. (2006). Development of the Grammar and Phonology Screening (GAPS) test to assess key markers of specific language and literacy difficulties in youg children. International Journal of Language \{\&\} Communication Disorders, 41(5), 513-540.

Gascoigne, M. (2006). “Supporting children with speech, language and communication needs within integrated children's services” RCSLT Position Paper. London.

Gillon, G. T., \& McNeill, B. C. (2007). Integrated phonological awareness: An 
Running head: Speech and Language Therapy Service Delivery

intervention program for preschool children with speech-language impairment. Christchurch: University of Canterbury.

Grácio, A. (2014). Políticas Públicas de Educação Especial. Lisboa: Conselho Nacional de Educação (CNE).

Guimarães, I. (1995). Protocolo de Avaliação Orofacial. Lisboa: Fisiopraxis.

Guitar, B. (2014). Stuttering: An Integrated Approach to Its Nature and Treatment (4th ed.). Baltimore: Lippincott Williams \& Wilkins.

Guyer, B., Ma, S., Grason, H., Frick, K., Perry, D., Sharkey, A., \& McIntosh, J. (2009). Early childhood health promotion and its life course health consequences. Academic Pediatrics, 9(3), 142-149.

Harulow, S. (2013). Facing cuts? Keep calm and star negotiating. Bulletin - The Official Magazine of the Royal College of Speech \& Language Therapists, (February), 1215.

Hodson, B., \& Paden, E. (1991). Targeting intelligible speech: A phonological approach to remediation. San Diego: College-Hill Press.

Jacoby, G., Lee, L., Kummer, A., \& Levin, L. (2002). The number of individual treatment units necessary to facilitate functional communication improvements in the speech and language of young children. American Journal of Speech-Language Pathology, 11, 370-380.

Jesus, L., \& Lousada, M. (2010). Protocolo de Anamnese de Linguagem na Criança da Universidade de Aveiro [University of Aveiro's Case History Form for Child Language].

Jesus, L., Martinez, J., Santos, J., \& Joffe, V. (2016a). Effectiveness of Two Methods of Phonological Interventions for Speech Sound Disorders: Tabletop \& Tablet. In Proceedings of the American Speech-Language-Hearing Association Convention 
Running head: Speech and Language Therapy Service Delivery

2016 (p. 230). Philadelphia, USA.

Jesus, L., Martinez, J., Santos, J., \& Joffe, V. (2016b). Exploring the Views of Service Users on a Novel Intervention for Children with Speech Sound Disorders: Design and Pretesting. In Proceedings of the 30th World Congress of the International Association of Logopedics and Phoniatrics (p. 85). Dublin, Ireland.

Jesus, L., Santos, J., Martinez, J., Lousada, M., \& Pape, D. (2015). The Table to Tablet (T2T) Therapy Software Development Approach. In Proceedings of the 10th Iberian Conference on Information Systems and Technologies (pp. 57-60). Águeda, Portugal. http://doi.org/10.1109/CISTI.2015.7170549

Lancaster, G. (2008). Developing speech and language skills. London: Routledge.

Law, J., Boyle, J., Harris, F., Harkness, A., \& Nye, C. (2000). Prevalence and natural history of primary speech and language delay: findings from a recent systematic review of the literature. International Journal of Language \& Communication Disorders, 35, 165-188.

Lindsay, G., Dockrell, J. E., \& Mackie, C. (2005). Local education authorities â€ $€^{\mathrm{TM}}$ approaches to provision for children with specific speech and language difficulties in England and Wales. European Jorunal of Special Needs Education, 20(3), 329345. http://doi.org/10.1080/08856250500156053

Lousada, M., Jesus, L. M. T., Capelas, S., Margaça, C., Simões, D., Valente, A. R., ... Joffe, V. L. (2013). Phonological and articulation treatment approaches in Portuguese children with speech and language impairments: a randomized controlled intervention study. International Journal of Language \& Communication Disorders, 48(2), 172-187. http://doi.org/10.1111/j.14606984.2012.00191.x

Lousada, M., Mendes, A., Valente, A., \& Hall, A. (2012). Standardization of a 
Running head: Speech and Language Therapy Service Delivery

Phonetic-Phonological Test for European Portuguese Children. Folia Phoniatrica et Logopaedica, 64(3), 151-156.

Mcginty, A. S., \& Justice, L. (2006). Classroom-Based versus Pull-Out Interventions: A Review of the Experimental Evidence. EBP Briefs, 1(1), 1-30.

McLeod, S., \& Harrison, L. J. (2009). Epidemiology of speech and language impairment in a nationally representative sample of 4- to 5-year-old children. Journal of Speech, Language, and Hearing Research, 52(5), 1213-1229.

McQuiston, S., \& Kloczko, N. (2011). Speech and language development: Monitoring process and problems. Pediatrics in Review, 32(6), 230-238.

Meline, T., Kauffman, C., Bender, F., Daly, G., Lang, C., \& Mcginty, A. (2010). A Speech-Language Pathologist's Dilemma: What is the best choice for service delivery in schools? EBP Briefs (Vol. 5). Bloomington: MN: Pearson.

Mendes, A., Afonso, E., Lousada, M., \& Andrade, F. (2013a). Teste FonéticoFonologico ALPE. Aveiro: Edubox.

Mendes, A., Afonso, E., Lousada, M., \& Andrade, F. (2014). Teste de Linguagem ALPE. Aveiro: Edubox.

Mendes, A., Afonso, M., Lousada, M., \& Andrade, F. (2013b). Teste FonéticoFonológico ALPE (TFF-ALPE). Aveiro: Edubox.

Mendes, A., Lousada, M., Valente, A., \& Hall, A. (2014). Validity and Reliability of the European-Portuguese Preschool Language Assessment ALPE. Folia Phoniatrica et Logopaedica, 66(3), 89-94. http://doi.org/10.1159/000365354

Mooss, A., Hartman, M., \& Ibanez, G. (2015). Manual development : A strategy for identifying core components of integrated health programs. Evaluation and Program Planning, 53, 57-64. http://doi.org/10.1016/j.evalprogplan.2015.08.004 Morgan, D., \& R, M. (2009). Sinlge-case research methods for the behavioral and 
Running head: Speech and Language Therapy Service Delivery

health sciences. Thousand Oaks, CA: Sage.

Nwosu, N. (2015). Systemic Review of the Prevalence of Speech and Language

Disorders in Nigeria. International Journal of Humanities and Social Science, 5(5), $130-133$.

Owens, R. (2011). Language Development: An Introduction (8th ed.). Boston: Pearson.

Paul, R., \& Norbury, C. (2012). Language Disorders from Infancy through

Adolescence: Listening, Speaking, Reading, Writing, and Communicating (4th ed.).

St. Louis, MO: Elsevier Mosby.

Pinborough-Zimmerman, J., Satterfield, R., Miller, J., Bilder, D., Hossain, S., \& McMahon, W. (2007). Communication disorders: Prevalence and comorbid intellectual disability, autism and emotional/behavioral disorders. American Journal of Speech- Language Pathology, 16, 359-367.

Popova, S., Lange, S., Burd, L., Shield, K., \& Rehm, J. (2014). Cost of speech-language interventions for children and youth with foetal alcohol spectrum disorder in Canada. International Journal of Speech and Language Pathology, 16(6), 571581.

Rosa, E. (2013). Cortes significativos na despesa pública com a educação, ciência e ensino superior no período 2011-2013. Available from www.eugeniorosa.com.

Rosa, E. (2016). Só no período 2001-2016 o Estado financiou o ensino privado com 4.464,4 milhões $€$ e os privados querem mais. Available from www.eugeniorosa.com.

Sandler, A. D., Brazdziunas, D., Cooley, W. C., Pijem, L. G., Hirsch, D., Kastner, T. A., ... Ruppert, E. S. (2001). Developmental Surveillance and Screening of Infants and Young Children. PEDIATRICS, 108(1), 192-195.

http://doi.org/10.1542/peds.108.1.192 
Running head: Speech and Language Therapy Service Delivery

Snowling, M., John, J., Bishop, D., \& Stothard, S. (2001). Educational attainments of school leavers with a preschool history of speech-language impairments. International Journal of Language \{\&\} Communication Disorders, 36(2), 173183.

Throneburg, R. N., Calvert, L. K., Sturm, J. J., Paramboukas, A. A., \& Paul, P. J. (2000). A comparison of service delivery models: Effects of curricular vocabulary skills in the school setting. American Journal of Speech-Language Pathology, 9, $10-20$.

Tomblin, J., Records, N., Buckwalter, P., Zhang, X., Smith, E., \& O’Brien, M. (1997). Prevalence of specific language impairment in kindergarten children. Journal of Speech, Language and Hearing Research, 40(6), 1245-1260.

Unicomb, R., Colyvas, K., Harrison, E., \& Hewat, S. (2016). Assessment of Reliable Change Using 95\{\%\} Credible Intervals for the Differences in Proportions: A Statistical Analysis for Case-Study Methodology. Journal of Speech, Language and Hearing Research, 58, 728-739. http://doi.org/10.1044/2015

Wilcox, M. J., Kouri, T. A., \& Caswell, S. B. (1991). Early language intervention: A comparison of classroom and individual treatment. American Journal of SpeechLanguage Pathology, 1, 49-60.

Willoughby, K. A., Chan, B. T. B., \& Marques, S. (2016). Using simulation to test ideas for improving speech language pathology services. European Journal of Operational Research, 252, 657-664. http://doi.org/10.1016/j.ejor.2016.01.029 World Health Organization. (2001). ICF: International Classification of Functioning, Disability and Health. Geneva: World Health Organization.

Yairi, E., \& Ambrose, N. G. (2005). Early Childhood Stuttering For Clinicians by Clinicians. Austin, Texas: Pro-ed. 
Running head: Speech and Language Therapy Service Delivery

Yaruss, J., \& Quesal, R. (2006). Overall Assessment of the Speaker's Experience of Stuttering (OASES): Documenting multiple outcomes in stuttering treatment. Journal of Fluency Disorders, 31, 90-115.

Yin, R. (2009). Case study research: Design and methods (4th ed.). Thousand Oaks: Sage. 
Running head: Speech and Language Therapy Service Delivery

\section{Highlights}

- An alternative model for specialised and differentiated care network of Speech and Language Therapy paediatric services for under-resourced countries.

- Objective evidence of the impact of the service delivery model in children.

- The best practices should be the basis of a service delivery model.

- It is very important to ensure that the right resources and conditions are in place when implementing these practices. 
Running head: Speech and Language Therapy Service Delivery

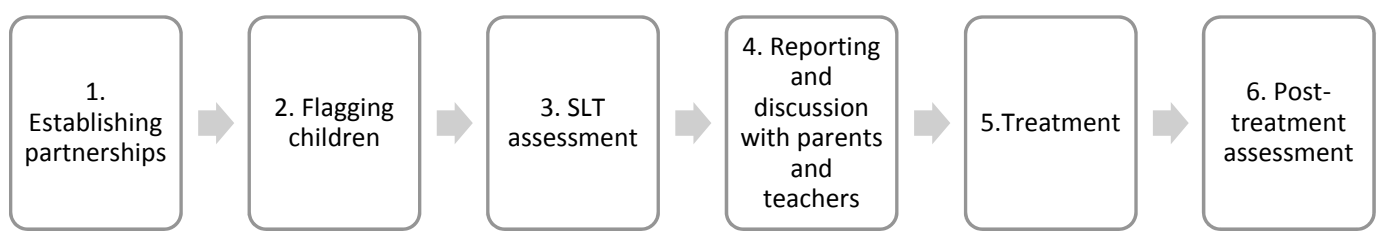

Figure 1 - The six step process of the SLT service model 
Running head: Speech and Language Therapy Service Delivery

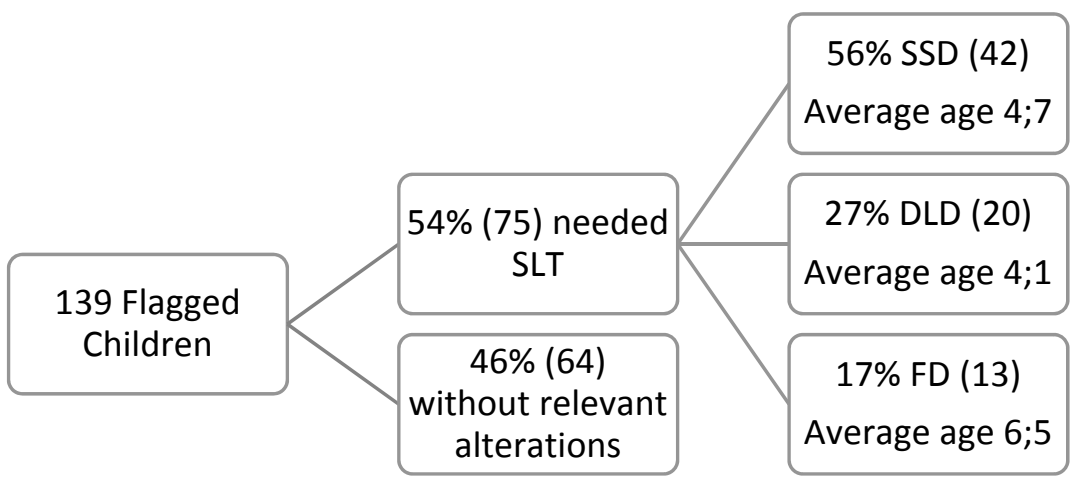

Figure 2 - Number of children flagged 
Running head: Speech and Language Therapy Service Delivery

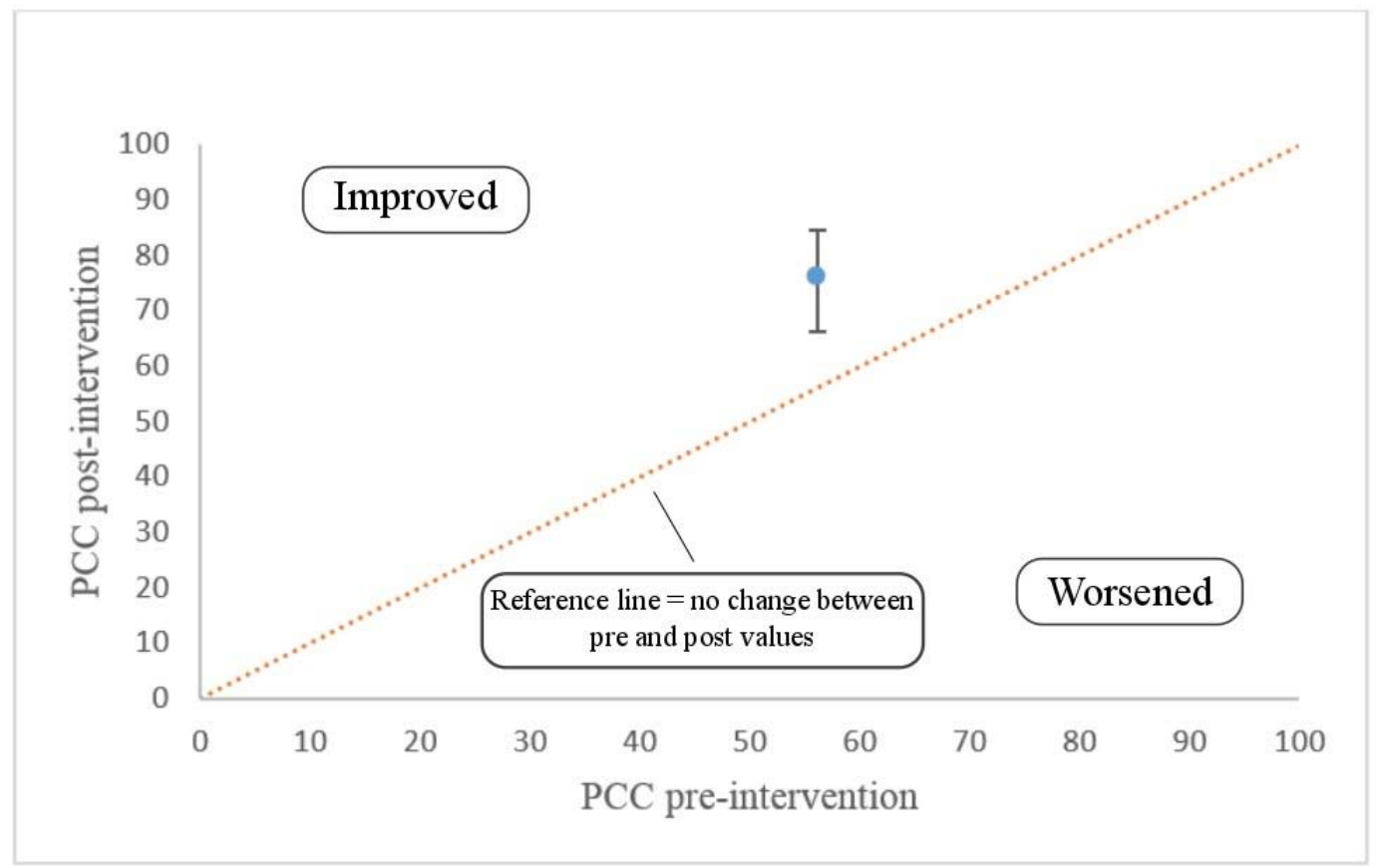

Figure 3 - Reliable Change Index Plot Case Study 1: Speech Sound Disorders 
Running head: Speech and Language Therapy Service Delivery

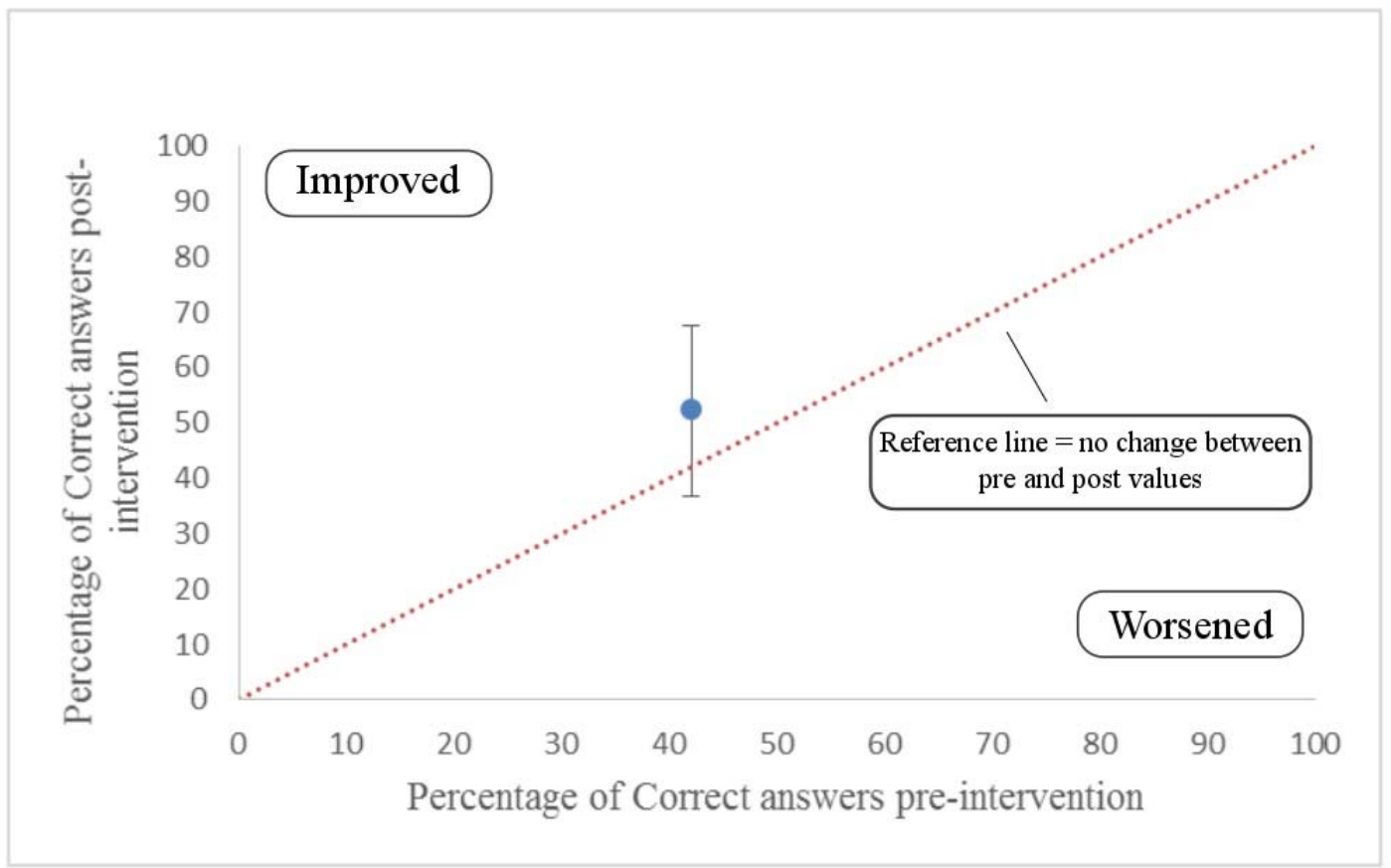

Figure 4 - Reliable Change Index Plot Case Study 2 - Expressive Language:

Developmental Language Disorder 
Running head: Speech and Language Therapy Service Delivery

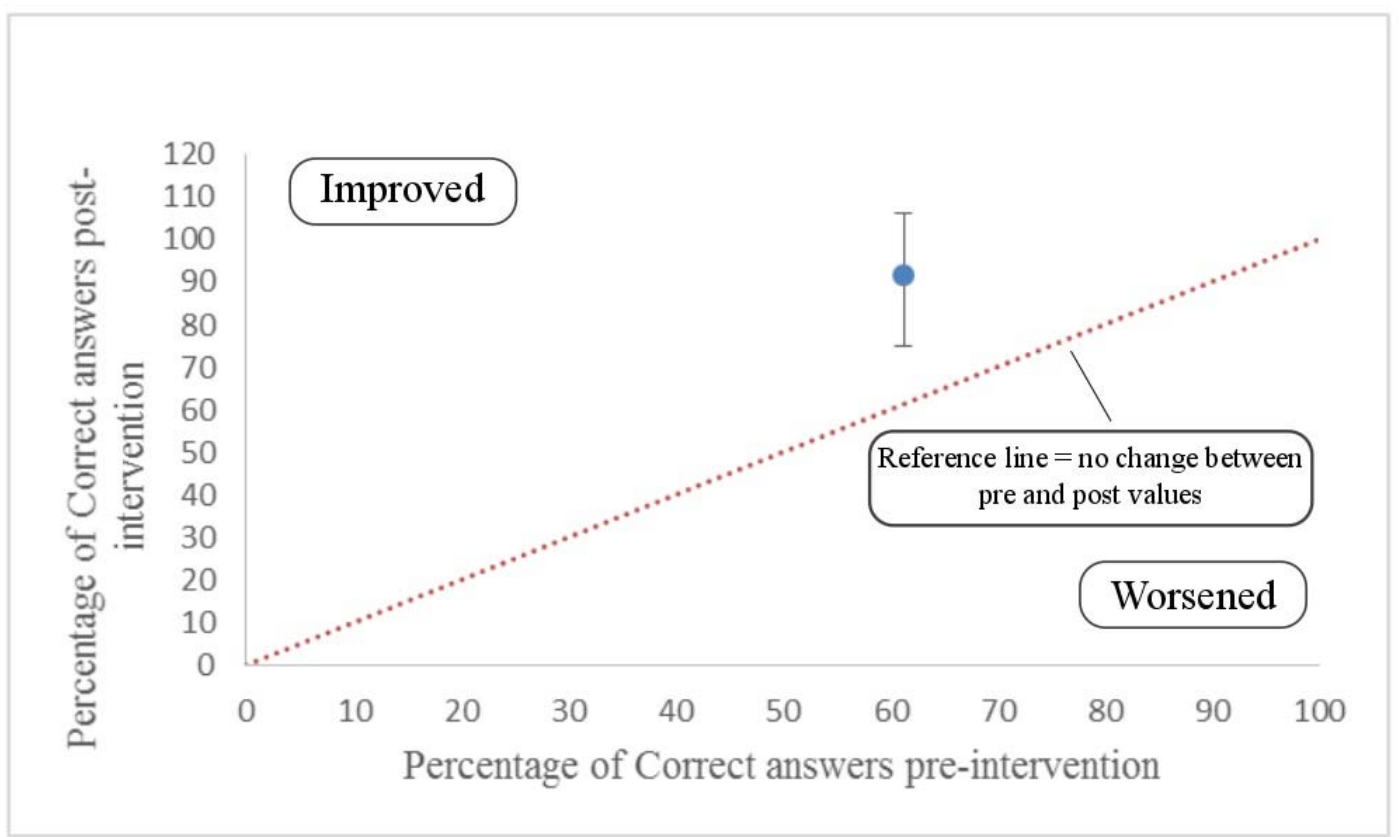

Figure 5 - Reliable Change Index Plot Case Study 2 - Receptive Language:

Developmental Language Disorder 
Running head: Speech and Language Therapy Service Delivery

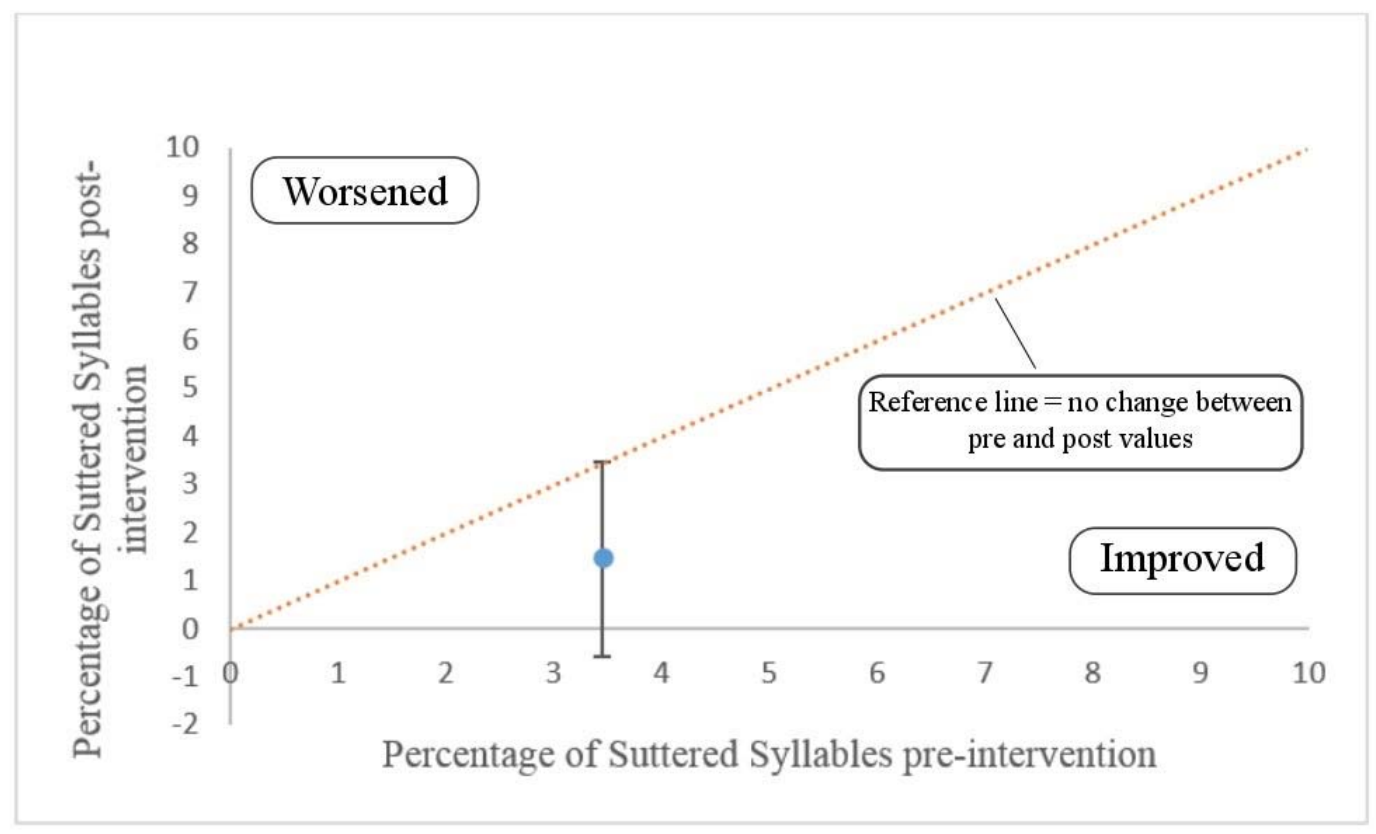

Figure 6 - Reliable Change Index Plot Case Study 3: Fluency Disorders 